\title{
Consequences of volcano sector collapse on magmatic storage zones: insights from numerical modeling
}

\author{
V. Pinel ${ }^{\mathrm{a}}$, F. Albino ${ }^{\mathrm{b}}$ \\ ${ }^{a}$ ISTerre, Université de Savoie, IRD, CNRS, F73376 Le Bourget du Lac, France \\ ${ }^{b}$ Nordic Volcanological Center, Institute of Earth Sciences, University of Iceland, 101 \\ Reykjavik, Iceland
}

\begin{abstract}
Major volcano flank collapses strongly affect the underlying magmatic plumbing system. Here, we consider the magma storage zone as a liquid pocket embedded in an elastic medium, and we perform numerical simulations in two-dimensional axisymmetric geometry as well as in three dimensions in order to evaluate the consequences of a major collapse event. We quantify the pressure decrease induced within and around a magma reservoir by a volcano flank collapse. This pressure reduction is expected to favour replenishment with less evolved magma from deeper sources. We also estimate the impact of the magma pressure decrease, together with the stress field variations around the reservoir, on the eruptive event associated with the edifice failure. We show that, for a given magma reservoir geometry, the collapse of a large strato-volcano tends to reduce the volume of the simultaneous eruption; destabilization of large edifices may even suppress magma emission, resulting in phreatic eruptions instead. This effect is greater for shallow reservoirs, and is more pronounced for spherical reservoirs than for
\end{abstract}

Email address: Virginie.Pinel@univ-savoie.fr (V. Pinel) 
vertically-elongated ones. It is reduced for compressible magmas containing a large amount of volatiles. Over a longer time scale, the modification of pressure conditions for dyke initiation at the chamber wall may also explain an increase in eruption rate as well as an apparent change of magma storage location.

Keywords: Edifice flank collapse, numerical modeling

\section{Introduction}

2

Large flank collapses have been recognized as common phenomena in the long-lived evolution of volcanic edifices. A large number of studies focus on the causes of, and/or triggers for, these destabilization events. They show that the origin of the destabilization can be related to exogenous processes such as weathering, but in most cases volcanic activity itself is involved (Mc Guire, 1996). In particular, the ability of magmatic intrusions to favour large flank collapse either during vertical dyke emplacement or during sill formation has been observed in the field (Famin and Michon, 2010), and investigated through modeling (Paul et al., 1987; Iverson, 1995). Siebert (1992) emphasized the potential hazards represented by sector collapses, which fully justify studies investigating volcano stability (Voight and Elsworth, 1997; Borselli et al., 2011). From a risk assessment perspective, the direct impact of a sudden and drastic sector collapse is also investigated through studies or modelling related to the volume and extension of the associated debris avalanche deposits (Borselli et al., 2011).

Another field of study encompasses describing and quantifying the consequences of such an event on the magmatic plumbing system evolution. The 
long-term history of volcanic edifices reveals that partial destruction of an edifice is usually followed by a change in eruption rate and/or magma composition (Presley et al., 1997; Hildenbrand et al., 2004; Hora et al., 2007; Longpré et al., 2010; Boulesteix et al., 2012). For oceanic volcanoes, this observation has usually been related to an increase in decompression melting subsequent to collapse (Presley et al., 1997; Hildenbrand et al., 2004), although Manconi et al. (2009) also evoked the depressurisation of a magmatic storage zone. For continental volcanoes, Pinel and Jaupart (2005), using an analytical elastic model for the two-dimensional plane strain approximation, quantified the pressure decrease induced within a magmatic reservoir by the partial destruction of an edifice. They also detailed the influence of such an event on the volume of magma erupted during the failure event.

Meanwhile, other surface load variations, occurring over a larger time scale, have been proven to have a significant impact on eruptive behaviour. In particular, a temporal correlation is observed between ice retreat induced by climate warming and volume of magma erupted, with an increase of eruption rates during postglacial periods (Jellinek et al., 2004; Sinton et al., 2005). The effect of ice retreat on both magma melting and storage has been investigated (see Sigmundsson et al. (2010) for a review). More recently, new modeling has shown that magma propagation within the upper crust is also affected by ice unloading, with an increased likelihood of magma storage within the crust during transport towards the surface. This is in good agreement with some geodetic observations performed around Vatnajökull ice cap in Iceland (Hooper et al., 2011).

In this study, we calculate the pressure reduction induced by a sudden 
flank collapse event within and around a magma storage zone located beneath a volcanic edifice. We only consider one-shot catastrophic flank collapses, rather than the effects of large, progressive landslides. We then quantify how the flank collapse affects the volume of erupted magma during the associated eruption, resulting from the storage zone withdrawal. Results are derived from numerical simulations incorporating the equation of elasticity, performed with the commercial software COMSOL both in axisymmetric geometry and in three dimensions. We also discuss the potential impact of large flank collapses on the long-term eruptive history, based on petrological observations.

\section{Pressure decrease induced by a volcano flank collapse}

Broadly speaking, a major sector collapse is equivalent to a surface unloading event. In reality, the edifice portion which fails is not removed from the Earth's surface, but is redistributed over a larger area. As previously shown by Pinel and Jaupart (2005), using analytical solutions, and by Albino et al. (2010), using numerical models in axisymmetric geometry, an unloading event always induces a pressure decrease within the underlying crust. This pressure reduction is of the same order of magnitude as the load removed from the surface.

\subsection{A conical load removed over an elastic half-space}

If we consider the crust to be an elastic, homogeneous medium characterized by its Young's modulus, E, and Poisson's ratio, $\nu$, the stress changes induced at depth by a conical load can be derived by integration of the point load solution. At the axis, the vertical stress due to a cone of radius, $R_{e}$, and 
maximum height, $H_{e}$, as a function of depth below the surface, $z$, is given by:

$$
\sigma_{z z}=P_{e}\left[1-\frac{z}{\sqrt{R_{e}^{2}+z^{2}}}\right]
$$

with $P_{e}=\rho_{c} g H_{e}$, where $\rho_{c}$ is the load density. The horizontal components are equal and given by Pinel and Jaupart (2000):

$$
\begin{array}{lccc}
\sigma_{r r}=\sigma_{\theta \theta}= & \frac{P_{e}}{2}\left[(1+2 \nu)-2(1+\nu) \frac{z}{R_{e}} \ln \left(\frac{R_{e}+\sqrt{R_{e}^{2}+z^{2}}}{z}\right)+\frac{z}{\sqrt{R_{e}^{2}+z^{2}}}\right] & \text { for } \mathrm{z}>0 \\
\sigma_{r r}=\sigma_{\theta \theta}= & \frac{P_{e}}{2}(1+2 \nu) & \text { for } \mathrm{z}=0,
\end{array}
$$

72 It follows that the pressure, $P$, defined as one third on the stress tensor trace, induced by a conical load, is equal to:

$$
\begin{array}{cc}
P=\frac{2 P_{e}}{3}(1+\nu)\left[1-\frac{z}{R_{e}} \ln \left(\frac{R_{e}+\sqrt{R_{e}^{2}+z^{2}}}{z}\right)\right] & \text { for } \mathrm{z}>0 \\
P= & \text { for } \mathrm{z}=0
\end{array}
$$

Stress and pressure reduction induced by the removal of conical load are shown in figure 1 . The stress component most affected by the load is, as expected, the vertical one $\sigma_{z z}$. The amplitude of the perturbation is greatest at the surface, and is directly related to the height of the load removed. The pressure reduction decreases with depth and becomes negligible at depths greater than three times the radius of the load.

\subsection{A conical load removed from above a magmatic reservoir}

Most tomographic studies performed on volcanoes (Monteiller et al., 2005; Prôno et al., 2009) reveal that the crust is far from being homogeneous around a magmatic system. In particular, shallow magma storage zones have been detected in many locations by either petrologic, seismic or geodetic studies (Gardner et al., 1995; Sturkell et al., 2006; Peltier et al., 2008). The pressure 
reduction induced by an unloading event within these magma pockets will depend both on the crustal deformation and on the equation of state of the melt embedded in the crust. Here we consider an ellipsoidal magmatic reservoir filled with fluid, embedded in an homogeneous elastic crust. Initially the liquid has the same density as the surrounding crust and is characterized by its bulk modulus, $K$. We only deal with the perturbation induced by a conical load removed from the Earth's surface, on which the initial stress field has no influence.

Within the magma reservoir the pressure change, $\Delta P$, is related to the reservoir volume change, $\Delta V$, through the bulk modulus definition:

$$
\Delta P=-K \frac{\Delta V}{V}
$$

with $V$ being the initial volume of the reservoir.

The change in reservoir volume is also a function of the chamber wall displacement, which depends on both the conical load and the magma pressure change. This volume change is calculated numerically, using the equations of elasticity with the commercial software COMSOL. The domain of calculation is a $100^{*} 100 \mathrm{~km}$ square box with a mesh of about 100000 triangular units that is refined around the volcanic edifice and magma reservoir. No displacement perpendicular to the boundary is allowed at the basal and lateral boundaries; the upper boundary is considered as being a free surface. The load is modeled with a normal stress applied at the upper surface, and a normal stress equal to the magma overpressure is applied at the reservoir walls. Numerical solutions have been validated using well-known analytical solutions as detailed in Albino et al. (2010). Pressure reduction within and around the magma reservoir induced by a conical load of $2 \mathrm{~km}$ radius, $1 \mathrm{~km}$ 
height, and density $2800 \mathrm{~kg} / \mathrm{m}^{3}$, is shown in figure 2 for two different chamber geometries: a spherical chamber, and a vertically-elongated chamber (prolate shape). Calculations are performed for a chamber top at $1 \mathrm{~km}$ depth and with a maximum chamber radius of $1 \mathrm{~km}$. The pressure variation within the crust departs strongly from the homogeneous case (figure 1) in the vicinity of the reservoir, this difference being more pronounced for the spherical reservoir than for the prolate one. An increase in pressure is even observed (negative values of the pressure reduction) at the chamber margins, the effect being most extreme at the chamber top. This is due to the deformation of the reservoir wall induced by the unloading event and partially counterbalanced by pressure variations within the magma reservoir. Within the magma reservoir, pressure always decreases as a consequence of the unloading event, the effect being, once again, larger in the case of the spherical reservoir than in the case of the prolate one. The amplitude of the magma pressure reduction increases with the value of the bulk modulus. This can be explained by the fact that for incompressible magmas (larger value of $\mathrm{K}$ ) no reservoir volume change occurs, thus all the volume reduction induced by the unloading event has to be compensated by a pressure reduction within the chamber. The effect of compressibility is shown in figure 3. In a compressible magma, buoyancy forces appear due to magma density variation; however since the model used here is valid in most of natural cases, as discussed by Pinel and Jaupart (2005), these forces have not been included here.

Figure 5 shows the pressure reduction within a spherical reservoir with a top at $1 \mathrm{~km}$ depth, induced by the removal of the upper $20 \%$ of the edifice, which corresponds to a mean value based on field observations (figure 
4a). This pressure reduction is more marked when considering larger edifices and smaller magma reservoirs. Calculations performed also show that the amplitude of the pressure reduction decreases for deeper magma reservoirs and is less marked in the case of a prolate reservoir than in a spherical one.

\section{Effect of volcano flank collapse on an ongoing eruption}

As described above, partial destruction of an edifice always induces a pressure decrease in the underlying storage zone. Simultaneously, this drastic change in surface load strongly modifies the stress field at the reservoir walls, and thus presumably dyke initiation and closure in this zone. While longterm conduit systems develop at the surface of silicic strato-volcanoes, this shallow level conduits are connected to deeper reservoirs via dykes as shown by deformation data (Mattioli et al., 1998), seismicity (Roman et al., 2006), and magma flow studies (Costa et al., 2007). Thus it is important to consider dyke opening and closure at the reservoir walls when dealing with magma transport to the surface.

\subsection{Principle}

For any given state of stress, one may define a threshold pressure, $P_{r}$, required for dyke initiation at the chamber wall. Here, we consider that once this pressure threshold is reached within the magma reservoir, a dyke initiates and magma leaves the storage zone to reach the surface and feed an eruption, such that pressure within the magma chamber cannot exceed this threshold value. Following Albino et al. (2010), we consider that tensile rupture of the reservoir wall occurs when the deviatoric part of the hoop stress exceeds the tensile strength, $T_{s}$, of host rocks. This criterion is consistent 
with the rupture criterion used in dyke propagation studies (Lister, 1990). Once a dyke has initiated, magma pressure within the reservoir decreases until it reaches a second threshold value, $P_{c l}$, at which point the dyke closes (Pinel et al., 2010). It follows that the volume of erupted magma is directly proportional to the pressure difference: $\Delta P_{e}=P_{r}-P_{c l}$.

We consider an initial state, corresponding to the situation just before the edifice partial destruction, with a pressurized storage zone. For this initial state, we can define the two threshold values, $P_{r}(i)$ and $P_{c l}(i)$ (see figure 6). As magma intrusions often acts as the triggers for edifice destabilization (Mc Guire, 1996), we make the assumption that the system is about to erupt, such that the magma pressure, $P(i)$, is equal to the threshold value required for dyke initiation, $P_{r}(i)$. A major collapse of the edifice then occurs, and our final state is a truncated edifice. The unloading event results in a pressure reduction $(\Delta P)$ within the magma reservoir, such that the final magma pressure within the reservoir is $P(f)<P(i)$. In the final state, the two threshold pressures, here denoted $P_{r}(f)$ and $P_{c l}(f)$ are different from the ones in the initial state (see figure 6). Based on the evolution of the threshold pressures, which can either increase or decrease, three different scenarios can result. Where the pressure difference, $P-P_{c l}$, increases with the edifice partial destruction (case 1 of figure 6 , where $P(f)-P_{c l}(f)>P(i)-P_{c l}(i)$ ), the edifice collapse is followed by an eruption with a volume of erupted magma larger that it would have been in the absence of edifice destruction. Where the pressure difference, $P-P_{c l}$, decreases with the edifice partial destruction (case 2 of figure 6 , where $P(f)-P_{c l}(f)<P(i)-P_{c l}(i)$ ), the erupted volume associated with the edifice collapse is smaller that it would have been in 
absence of edifice destruction. In the event of the magma pressure within the reservoir dropping below the threshold pressure for dyke closure (case 3 of figure 6 , where $P(f)<P_{c l}(f)$ ), the incipient eruption is aborted and no magma is erupted at the surface as a consequence of the edifice collapse.

Factors determining which scenario occurs are the initial edifice size and geometry, the amount of edifice destruction, the size, shape and depth of the magma reservoir, and magma gas content.

\subsection{Numerical results for axisymmetric models}

We performed numerical simulations for edifices of different initial sizes, with various reservoir depths and sizes, and two different reservoir shapes: a spherical one and a vertically-elongated one (prolate shape). We considered the effect of partial destruction, corresponding to the removal of the upper $20 \%$ of a strato-volcano with a conical shape and a slope of 30 degrees (figure 9 B). A slope of 30 degrees is an upper limit for the upper part of strato-volcanoes based on a compilation of Digital Elevation Models, and corresponds to the maximum frequency of major slope failure events on Quaternary volcanoes (Voight and Elsworth, 1997); collapse of $20 \%$ of the initial volcano can be considered as a mean value based on a compilation of field observations (figure 4a). In all simulations we consider an incompressible magma; effects of compressibility and gas content are discussed at the end of this section, and in section 5 .

For a spherical reservoir located at $1 \mathrm{~km}$ depth beneath the volcanic edifice, each of the three scenarios previously described (figure 6) can occur (see figure $7 \mathrm{~b}$ ). When the collapse affects small edifices, the erupted volume is larger than, but still close to, that expected in the absence of edifice 
destruction. As the edifice size increases, so the volume of erupted magma after the edifice collapse tends to decrease. This volume reduces to zero when large strato-volcanoes are partially destroyed by flank collapse, resulting in the abortion of any incipient eruption. For a shallower magma reservoir, a smaller edifice size is required to reach the point of aborted eruption, (see figure 7 a), whereas all effects of edifice collapse on erupted magma volume are reduced with a deeper chamber (see figure $7 \mathrm{c}$ ).

Effects of an edifice collapse event on the subsequent eruption also depend on the magma reservoir shape. Figure 8 shows that, for a prolate reservoir, the influence of the collapse is smaller, and a larger edifice size is required in order to decrease the amount of erupted magma, than for a spherical reservoir at the same depth. Above a prolate reservoir with a top at one kilometer depth, magma eruption is only aborted when the edifice radius is greater than $6 \mathrm{~km}$.

For storage zones located at a few kilometers depth beneath the volcanic edifice, it is possible to include compressibility effects (see section 5), which can be important when volatiles are present. The inclusion of compressibility effects mainly acts to reduce the magma pressure decrease within the storage zone following the unloading event, as shown in figure 3. It follows that the volume of erupted magma will thus be larger than in the case of an incompressible magma. Larger edifice size is required to counteract this, and reduce the amount of erupted magma.

\subsection{D effects: Influence of the shape of the load removed}

To be more realistic, we also carry out 3D models in order to simulate asymmetric flank collapses and mimic the resulting horseshoe- shaped craters 
of the final edifice geometry that are observed at many strato-volcanoes, such as Mount St Helens (Cascades, USA), Bezymianni and Shiveluch (Kamtchatka, Russia) or Galunggung (Indonesia). The volume of the landslide remains fixed at $20 \%$ of the initial volcanic edifice, but the collapse now occurs only at one side of the volcano (figure $9 \mathrm{C}$ ). The unloading associated with the edifice collapse is thus asymmetric, with potential consequences for failure conditions at the reservoir wall. The removed part of the edifice is re-distributed as a thin deposit layer around the volcano. This layer has a constant thickness from the base of the edifice to a distance of ten times the edifice radius, and is only emplaced in a sector of $\pm 30^{\circ}$ from the collapse flank. The runout and sector angle are based on field observations, as shown in figure $4 \mathrm{~b}$.

For comparison, elastic parameters are the same as in the previous axisymmetric models. We run models for the same reservoir geometry: a sphere with a $3 \mathrm{~km}$ radius, with a top situated at two different depths (1 and $3 \mathrm{~km}$ ). Three different values for the initial edifice radius $(1,3$ and $6 \mathrm{~km})$ are considered. Table 1 gives the comparison between symmetric and asymmetric collapses. Here the symmetric case is recalculated so that the removed part of the edifice is re-distributed as a deposit layer of constant thickness from the edifice to a distance equal to 5 times the edifice radius. This distance is chosen in order to obtain the same order of magnitude for the deposit thickness as for the asymmetric case.

Values of the ratio of erupted volume after collapse to erupted volume without collapse are almost the same for both collapse geometries. The erupted volume after collapse only remains the same as that without any edifice destruction for small edifices (case 1, for an edifice of $1 \mathrm{~km}$ radius). 
However, this erupted volume decreases when the initial edifice size increases (case 2 , for an edifice of $3 \mathrm{~km}$ radius and a chamber top at $1 \mathrm{~km}$ depth, or for an edifice of $6 \mathrm{~km}$ radius and a chamber top at $3 \mathrm{~km}$ depth). For large edifices and shallow storage zones, no magma is erupted, since eruption is aborted by the collapse event (case 3 for an edifice of $6 \mathrm{~km}$ radius and a chamber depth of $1 \mathrm{~km}$ ).

The closure pressure tends to decrease for asymmetric failure compared to symmetric failure. This effect produces a small increase in erupted volume compared to the symmetrical model for case 2 (Table 1). Calculated differences are minimal between the two failure geometries, with a difference in total erupted volume of only a few percent. In the same way, our results for erupted volume do not change significantly when taking into account the mass load redistribution due to runout deposits at the periphery of the volcano.

From these calculations, it appears that the results are not significantly affected by the collapse geometry; thus the less time-consuming axisymmetric models, can be used to perform parametric studies.

\subsection{Phreatic eruptions}

Several large volcanic failure events have not resulted in emission of juvenile material, but instead lead to a phreatic eruption. Such phreatic events were defined by Siebert et al. (1987) as Bandai-type eruptions after the name of the Bandai-san volcano in northeast Japan, which produced large phreatic explosions associated with a major debris avalanche in 1888 (Yamamoto et al., 1999). At Bandai-san, the volcanic failure was triggered by an earthquake and there is no direct evidence of magma involvement in this 
catastrophic event. As no juvenile products were erupted, the straightforward conclusion is that no magma was present at shallow level. However, pressurized fluids had been stored at a shallow depth, and a heat source is necessary to explain the vigorous hydrothermal system. Our results provide an alternative framework to interpret such phreatic events, in which magma might be trapped in reservoirs beneath the edifice. We show that for shallow reservoirs, even if magma was present, a large edifice collapse could potentially abort the incipient eruption.

\section{Effect of edifice destabilization on the long-term eruptive history}

The three main modifications documented with regard to the erupted magma after a major flank collapse are: an increase in eruption rate (Beget and Kienle, 1992; Siebert et al., 1995; Boulesteix et al., 2012), a change in erupted magma composition towards less evolved and denser magmas (Manconi et al., 2009; Longpré et al., 2010; Boulesteix et al., 2012), and a change in magma storage pressure (Rutherford and Devine, 2008).

As shown in section 2, an edifice flank collapse always causes a pressure decrease within underlying storage zones. Where the shallow reservoir is still connected to a deeper source of magma, this reservoir depressurisation should induce a rapid replenishment as observed after a reservoir withdrawal due to an eruptive event (Lu et al., 2010). The deeper source is expected to contain more primitive magmas, and the replenishment should thus increase the amount of less differentiated magmas within the shallow storage zone. A reduced edifice size also allows the eruption of denser products which would otherwise have stalled at shallow depth (Pinel and Jaupart, 2000). 
The evolution of the threshold pressure required for dyke initiation, which corresponds to the maximum pressure within the reservoir, should have an impact over a longer time scale. At Mount St Helens, the pressure evolution of the storage zone can be seen through petrological studies of rocks spanning the last thousand years (Gardner et al., 1995; Rutherford and Devine, 2008). The observed pressure range is between $130 \mathrm{MPa}$ and $300 \mathrm{MPa}$, with several episodes of storage pressure reduction occurring over periods of a few years. The most recent episode of storage pressure decrease corresponds to the renewed activity in 2004-2006, with a pressure decrease in the order of $50 \mathrm{MPa}$ compared to the magma erupted in 1980. Such episodes of pressure decrease have been interpreted as being due to a rise of the storage zone (Gardner et al., 1995). However, it has been shown that each episode of pressure decrease follows directly on from a large edifice destabilization, such as the one which occurred in 1980 (Hopson and Melson, 1980; Hausback and Swanson, 1990). Pinel and Jaupart (2003) and Pinel et al. (2010) propose that this pressure variation could be explained by a magma pressure decrease within a fixed storage zone induced by the edifice partial destruction rather than by upward migration of the storage location. At Mount St Helens, the petrological data are thus consistent with a decrease of the threshold pressure required for dyke initiation following flank failure. Where the shallow reservoir is fed by a source of constant pressure at depth, such a decrease should result in an increase of the eruption rate (Pinel et al., 2010), in good agreement with the observations. 


\section{Discussion}

We investigate the influence of the reservoir shape by considering only vertically-elongated ellipsoids. Calculations with horizontally-elongated reservoirs (oblate shape) could have been performed, but the edifice collapse impact is only significant for shallow reservoirs, and it has been shown previously that shallow, oblate reservoirs strongly favour caldera formation (Roche, 2000; Geyer et al., 2006). Caldera collapse formation is a complex and specific phenomenon, already studied elsewhere (Pinel, 2011), and beyond the scope of this paper in relation to major flank collapse. Thus we choose to ignore oblate-shaped chambers here.

In this study we assume that rocks encasing the reservoir behave elastically. Volcano flank collapses are often sudden events. For instance, detachment of the northern flank of Mount St Helens, USA, in May 1980, occurred in a few seconds, as testified by eye-witnesses. Besides, we show that an unloading event significantly affects the stress field only at depths of less than three times the radius of the removed load (figure 1). At the time scale of an eruptive cycle, geodetic measurements recorded during replenishment or eruptive events (Sturkell et al., 2006; Lu et al., 2010; Lu and Dzurisin, 2010) prove that the elastic assumption is valid, at least for shallow reservoirs. This geophysical observation justifies our elastic assumption when looking at the impact of a major flank collapse on the subsequent eruptive event for continental volcanoes, for which the lateral extension of the edifice remains small compared to the elastic crustal thickness. Estimations of the Maxwell relaxation time for upper crustal rocks in volcanic areas are around 30-80 ky (Jellinek et al., 2004), and the usual duration for cone-building episodes 
is less than 100 ky for continental volcanoes (Davidson and DeSilva, 2000). Based on this consideration, our elastic model can still be used to discuss the influence of a major flank collapse on the long-term eruptive history of a given continental volcanic system. However, the elastic assumption becomes less valid when looking at the effect of destabilization on large oceanic volcanoes. The largest debris avalanche deposits (reaching $5000 \mathrm{~km}^{3}$ ) are observed around large ocean-island volcanoes (Mc Guire, 1996). The lateral extension of the removed load is then close to, or even larger than, the elastic crustal thickness. For instance, the El Golfo landslide, which affected El Hierro island in the Canary Islands, had an inferred lateral extension of more than $10 \mathrm{~km}$, for an elastic crustal thickness in this area of around $20 \mathrm{~km}$, based on seismic and gravity data (Watts et al., 1997). To investigate the impact of these large-scale flank collapses on the magmatic plumbing system of oceanic volcanoes, it would be necessary to take the viscous response of the mantle into consideration, too, as proposed by Sigmundsson et al. (2012) in their study of the influence of long-term ice retreat on magma storage zones.

The model developed in this paper deals with a magma storage zone beneath the volcanic edifice such that it cannot account for decompression of the magma emplaced at shallow depth within the volcanic edifice. This effect should be taken into account to fully describe what occurred during the May 1980 eruption of Mount St Helens, where the volcano collapse was followed by a $1 \mathrm{~km}^{3}$ Plinian ash eruption (Bradley and Myers , 2000). However the effect of magma compressibility within the chamber can also be included when buoyancy forces induced by magma density variations remain small relative to magma pressure changes (see Pinel and Jaupart (2005) for a complete dis- 
cussion). This condition is verified for magma with a few percent of volatiles stored at depths greater than a few kilometers.

\section{Conclusion}

Numerical simulations using the elasticity equations help to constrain the potential impact of a major volcano flank collapse on the ongoing eruption, as well as the longer term eruptive history, of continental volcanoes. Development of models taking into account the viscous response of the mantle would be necessary in order to model more precisely the potential consequences of the larger flank collapses affecting oceanic volcanoes.

\section{Acknowledgments}

The authors thank the Editor Malcolm J. Rutherford and two anonymous reviewers for providing helpful comments. We also thank Francesca van Wyk de Vries for English corrections. 


\section{References}

Albino, F., Pinel, V., Sigmundsson, F., 2010. Influence of surface load variations on eruption likelihood: Application to two Icelandic subglacial volcanoes, Grimsvötn and Katla. Geophys. J. Int. 181, 1510-1524, doi: 10.1111/j.1365-246X.2010.04603.x.

Beget, J. E., Kienle, J., 1992. Cyclic formation of debris avalanches at Mount St Augustine volcano. Nature 356, 701-704.

Boulesteix, T., Hildenbrand, A., Gillot P.-Y., Soler, V., 2012. Eruptive response of oceanic islands to giant landslides: New insigths from the geomorphologic evolution of the Teide-Pico Viejo volcanic complex (Tenerife, Canary). Geomorphology, 138, 61-73.

Borselli, L., Capra, L., Sarocchi, D., De la Cruz-Reyna, S., 2011. Flank collapse scenarios at volcan de Colima, Mexico: A relative instability analysis. J. Volcanol. Geotherm. Res. 208, 51-65.

Bradley, S. , Myers, B., 2000, Mount St. Helensfrom the 1980 Eruption to 2000, U.S. Geological Survey Fact Sheet 036-00.

Costa, A. , Melnik, O., Sparks, R. S. J., Voight, B., 2007, Control of magma flow in dykes on cyclic lava dome extrusion, G. Res. Lett., 34, doi:10.1029/2006GL027466.

Davidson, J., DeSilva, S., 2000. Composite volcanoes. In : Sigurdsson H (eds) Encyclopedia of volcanoes, Academic Press, London. 
Famin, V., Michon, L., 2010. Volcanic destabilization by magma injections in a detachment. Geology 38, 219-222, doi:10.1130/G30717.1.

Gardner, J. E., Rutherford, M., Carey, S., Sigurdsson, H., 1995. Experimental constraints on pre-eruptive water contents and changing magma storage prior to explosive eruptions of Mount St Helens volcano. Bull. Volcanol. $57,1-17$.

Geyer, A., Folch, A., Marti, J., 2006. Relationship between caldera collapse and magma chamber withdrawal: an experimental approach. J. Volcanol. Geotherm. Res. 157, 375-386.

Hausback, B. P., Swanson, D. A., 1990. Record of prehistoric debris avalanches on the north flank of Mount St. Helens volcano, Washington. Geoscience Canada 17, 142-145.

Hildenbrand, A., Gillot, P., Le Roy, I., 2004. Volcano-tectonic and geochemical evolution of an oceanic intra-plate volcano: Tahiti-Nui (french Polynesia). Earth Planet. Sci. Lett. 217, 349-365.

Hooper, A., Ofeigsson, B., Sigmundsson, F., Lund, B., Einarsson, P., Geirsson, H., Sturkell, E., 2011. Increased crustal capture of magma at volcanoes with retreating ice cap. Nature Geoscience.

Hopson, C. A., Melson, W. G., 1980. Compositional trends and eruptive cycles at Mount St. Helens. Geoscience Canada 17, 131-141.

Hora, J. M., Singer, B. S., Wörner, G., 2007. Volcano evolution and eruptive flux on the thick crust of the Andean Central Volcanic Zone: ${ }^{40} \mathrm{Ar} /{ }^{39} \mathrm{Ar}$ constraints from Volcán Parinacota, Chile. GSA Bulletin 119, 343-362. 
Iverson, R. M., 1995. Can magma-injection and groundwater forces cause massive landslides on Hawaiian volcanoes. J. Volcanol. Geotherm. Res. 66, 295-308.

Jellinek, A. M., Manga, M., Saar, M. O., 2004. Did melting glaciers cause volcanic eruptions in eastern California? probing the mechanics of dike formation. J. Geophys. Res. 109, b09206, doi:10.1029/2004JB002978.

Lister, J. R., 1990. Buoyancy-driven fluid fracture: the effects of material toughness and low-viscosity precursors. J. Fluid Mech. 210, 263-280.

Longpré, M.-A., Troll, V. R., Walter, T. R., Hansteen, T. H., 2010. Volcanic and geochemical evolution of the Teno massif, Tenerife, Canary Islands: Some repercussions of giant landslides on ocean island magmatism. Geochem. Geophys. Geosyst. 10, q12017,doi:10.1029/2009GC002892.

Lu, Z., Dzurisin, D., 2010. Ground surface deformation patterns, magma supply, and magma storage at Okmok volcano, Alaska, from InSAR analysis:1. Co-eruptive deflation, July-August 2008. J. Geophys. Res. 115, (B00B03) doi:10.1029/2009JB006970.

Lu, Z., Dzurisin, D., Biggs, J., Wick Jr., C., McNutt, S., 2010. Ground surface deformation patterns, magma supply, and magma storage at Okmok volcano, Alaska, from InSAR analysis:1. Intereruption deformation, 19972008. J. Geophys. Res. 115, (B00B02) doi:10.1029/2009JB006969.

Manconi, A., Longpré, M.-A., Walter, T. R., Troll, V. R., Hansteen, T. H., 2009. The effects of flank collapses on volcano plumbing systems. Geology $37,1,099-1,102$. 
Mattioli, G., T. H. Dixon, F. F. Farina, E. S. Howell, P. E. Jansma, and A. L. Smith, 1998. GPS measurement of surface deformation around Soufriere Hills volcano, Montserrat from October 1995 to July 1996, Geophys. Res. Lett., 25, 34173420 .

Mc Guire, W., 1996. Volcano instability: A review of contemporary themes. Geological Society of London Special Publication 110, 1-23.

Monteiller, V., J.-L., G., Virieux, J., Okubo, P., 2005. An efficient algorithm for double-difference tomography and location in heterogeneous media, with an application to the Kilauea volcano. J. Geophys. Res. 110, doi:10.1029/2004JB003466.

Paul, A., Gratier, J. P., Boudon, J., 1987. A numerical model for simulating deformation of Mount St. Helens volcano. J. Geophys. Res. 92, 10,29910,312 .

Peltier, A., Famin, V., Bachélery, P., Cayol, V., Fukushima, Y., Staudacher, T., 2008. Cyclic magma storages and transfers at Piton de la Fournaise volcano (La Réunion hotspot) inferred from deformation and geochemical data. Earth Planet. Sci. Lett. 270, 180-188.

Pinel, V., 2011. Influence of preexisting volcanic edifice geometry on caldera formation. Geophysical Research Letters 38, doi:10.1029/2011GL047900.

Pinel, V., Jaupart, C., 2000. The effect of edifice load on magma ascent beneath a volcano. Phil. Trans. R. Soc. Lond. A 358, 1,515-1,532.

Pinel, V., Jaupart, C., 2003. Magma chamber behavior beneath a volcanic edifice. J. Geophys. Res. 108, (B2) 2072, doi:10.1029/2002JB001751. 
Pinel, V., Jaupart, C., 2005. Some consequences of volcanic edifice destruction for eruption conditions. J. Volcanol. Geotherm. Res. 145, 68-80, doi:10.1016/j.jvolgeores.2005.01.012.

Pinel, V., Jaupart, C., Albino, F., 2010. On the relationship between cycles of eruptive activity and volcanic edifice growth. J. Volcanol. Geotherm. Res. 194, 150-164, doi:10.1016/j.jvolgeores.2010.05.006.

Presley, T. K., Sinton, J. M., Pringle, M., 1997. Postshield volcanism and catastrophic mass wasting of the Waianae Volcano, Oahu, Hawaii. Bull. Volcanol. 58, 597-616.

Prôno, E., Battaglia, J., Monteiller, V., Got, J.-L., Ferrazini, V., 2009. Pwave velocity structure of Piton de la Fournaise volcano deduced from seismic data recorded between 1996 and 1999. J. Volcanol. Geotherm. Res. $184,49-62$.

Roche, O., 2000. Les mécanismes de formation des calderas: étude expérimentale et modélisation. Ph.D. thesis, Université Blaise Pascal.

Roman, D. C., J. Neuberg, and R. R. Luckett (2006), Assessing the likelihood of volcanic eruption through analysis of volcanotectonic earthquake fault-plane solutions, Earth Planet. Sci. Lett., 248, 244 252, doi:10.1016/j.epsl.2006.05.029.

Rutherford, M. J., Devine, J. D., 2008. Magmatic conditions and processes in the storage zone of the 2004-2006 Mount St Helens dacite. In : Sherrod, D. R., Scott, W. E. and Stauffer, P. H. (eds) A volcano rekindled: The 
renewed eruption of Mount St. Helens, 2004-2006, U.S. Geological Survey Professional Paper 1750.

Siebert, L., 1992. Threats from debris avalanches. Nature 356, 658-659.

Siebert, L., Beget, J. E., Glicken, H., 1995. The 1883 and late-prehistoric eruptions of Augustine volcano, Alaska. J. Volcanol. Geotherm. Res. 66, $367-395$.

Siebert, L., Glicken, H., Ui, T., 1987. Volcanic hazards from Bezymiannyand Bandai-type eruptions. Bull. Volcanol. 49, 435-459.

Sigmundsson, F., Albino, F., Schmidt, P., Lund, B., Pinel, V., Hooper, A., Pagli, C., 2012. Multiple effects of surface load changes and associated stress change on magmatic systems. To be published in McGuire, W. J. \& Maslin, M. A. (eds) Climate Forcing of Geological and Geomorphological Hazards, Wiley-Blackwell.

Sigmundsson, F., Pinel, V., Lund, B., Albino, F., Pagli, C., Geirsson, H., Sturkell, E., 2010. Climate effects on volcanism: Influence on magmatic systems of loading and unloading from ice mass variations with examples from Iceland. Phil. Trans. R. Soc. Lond. A 368, 2,519-2,534, doi: 10.1098/rsta.2010.0042.

Sinton, J., Gronvold, K., Saemundsson, 2005. Postglacial eruptive history of the western volcanic zone, Iceland. Geochem. Geophys. Geosyst. 6, q12009. (doi:10.1029/2005GC001021).

Sturkell, E., Einarsson, P., Sigmundsson, F., Geirsson, H., Olafsson, H., Pedersen, R., de Zeeuw-van Dalfsen, E., Linde, A. T., Sacks, S. I., Stefansson, 
R., 2006. Volcano geodesy and magma dynamics in Iceland. J. Volcanol. Geotherm. Res. 150, 14-34.

Tait, S., Jaupart, C., Vergniolle, S., 1989. Pressure, gaz content and eruption periodicity of a shallow, crystallising magma chamber. Earth Planet. Sci. Lett. 92, 107-123.

Voight, B., Elsworth, D., 1997. Failure of volcano slopes. Géotechnique 47, $1-31$.

Watts, A. B., Peirce, C., Collier, J. abd Dalwood, R., Canales, J. P., Henstock, T. J., 1997. A seismic study of lithospheric flexure in the vicinity of Tenerife, Canary Islands. Earth Planet. Sci. Lett. 146, 431-447.

Yamamoto, T., Nakamura, Y., Glicken, H., 1999. Pyroclastic density current from the 1888 phreatic eruption of Bandai volcano, NE Japan. J. Volcanol. Geotherm. Res. 90, 191-207. 
Table 1: Comparison between results obtained with a truncated edifice (2D axisymmetric calculation, figure $9 \mathrm{~B}$ ) and with a sector collapse (3D calculation, figure $9 \mathrm{C}$ ). Mass is redistributed at the volcano base: all around the volcano for the axisymmetric case, and in a wedge-shaped sector for the asymmetric flank collapse. Calculations are performed for a spherical reservoir with a $3 \mathrm{~km}$ radius, and a top at $1 \mathrm{~km}$ or $3 \mathrm{~km}$ depth, for three different initial edifice radii: 1,3 and $6 \mathrm{~km}$. The same experiments are represented by crosses in figure 7 .

Figure 1: Stress reduction under the centre of a conical load (2 km radius, $1 \mathrm{~km}$ height, density of $2800 \mathrm{~kg} / \mathrm{m}^{3}$ ) which is removed from the surface. Calculation is for an elastic half-space with Poisson's ratio equal to 0.25. The dotted line is for the vertical component of the stress tensor, $\sigma_{z z}$, the dashed line is for the horizontal components, $\sigma_{r r}=\sigma_{\theta \theta}$, and the solid line is for the pressure reduction, $P=(1 / 3)\left(\sigma_{r r}+\sigma_{\theta \theta}+\sigma_{z z}\right)$.

Figure 2: Pressure decrease within and around a magmatic reservoir, under the centre of a conical load ( $2 \mathrm{~km}$ radius, $1 \mathrm{~km}$ height, density of $2800 \mathrm{~kg} / \mathrm{m}^{3}$ ) which is removed from the surface. The chamber resides in an otherwise elastic homogeneous half-space with Young's modulus E = 30 GPa and Poisson's ratio $\nu=0.25$. In the absence of a magma chamber (black dashed curve), the pressure profile obtained is equivalent to the one given by equation 3 (solid line in figure 1). Other lines are for pressure profiles where there is a magma reservoir, with varying values of the magma bulk modulus (blue line, incompressible magma; purple line, $\mathrm{K}=20 \mathrm{GPa}$; red line, $\mathrm{K}=10 \mathrm{GPa}$; orange line, $\mathrm{K}=1 \mathrm{GPa}$; yellow line, $\mathrm{K}=0 \mathrm{GPa}$ ). a) The chamber is a sphere (radius $1 \mathrm{~km}$, depth to chamber top $1 \mathrm{~km}$ ). b) The chamber is a prolate ellipsoid (half-height $1 \mathrm{~km}$, half-width $0.25 \mathrm{~km}$, depth to chamber top $1 \mathrm{~km}$ ). 
Figure 3: Pressure reduction within the magma chamber $(\Delta P(K))$ induced by the removal of a surface conical load (radius $2 \mathrm{~km}$, height $1 \mathrm{~km}$, density 2800 $\mathrm{kg} / \mathrm{m}^{3}$ ) as a function of the bulk modulus, K, of the magma. Crustal Young's modulus and Poisson's ratio are equal to $30 \mathrm{GPa}$ and 0.25 , respectively. The pressure change is normalized by the pressure change in incompressible magma $\left(\Delta P_{\infty}\right)$. The shaded area shows the range of values characteristic of dry magmas (K between 1 and 20 GPa; Tait et al. (1989)). The solid curve is for the spherical reservoir and the dashed curve for the prolate one. 
Figure 4: a) Volume of major collapse versus edifice volume. Failure volumes are taken from Table 1 in Mc Guire (1996), except for Parinacota volcano (Hora et al., 2007). Edifice volumes before collapse are estimated using the present topography of the volcano. When no collapse scar is visible in the topography, corresponding to old events, the volume before collapse is taken to be equal to the present volume; when a large scar is visible, the volume before collapse is obtained by adding the present volume to the failure volume. The total current volume of each volcano, at present time, has been calculated by the numerical integration of SRTM (3" arc) elevation. For volume calculation, we assume that edifice extension stops when the slope becomes small $\left(<10^{\circ}\right)$, and we subtract the mean elevation of the basement to deduce volcano height. The ratio between the volcano collapse volume and the total edifice volume is between $10 \%$ and $30 \%$ (dashed lines). For all collapse models, we use the mean value of $20 \%$ (solid line) for this ratio. b) Runout distances of debris avalanches versus volcano radii. Runout distances are taken from Table 1 in Mc Guire (1996). Most volcanoes produce avalanches which travel to distances of around 6 times the radius of the edifice (lower dashed line). However, in certain conditions, such as Colima volcano, the deposits can travel up to 12 times the radius of the edifice (upper dashed line). A value of 10 is used in the $3 \mathrm{D}$ asymmetric modelling (solid line). 
Figure 5: Pressure reduction within the magma reservoir induced by the removal of the upper $20 \%$ of a conical edifice with a slope of 30 degrees. Results are presented as a function of the reservoir and edifice radius. Calculations are performed for a spherical reservoir with a top at $1 \mathrm{~km}$ depth, and filled with incompressible magma. Crustal Poisson's ratio is equal to 0.25.

Figure 6: a) Evolution of magma pressure, $P$, and threshold pressure for failure, $P_{r}$, induced by volcanic collapse. (b) Evolution of the erupted volume of magma following edifice destabilization. For a given reservoir geometry, the erupted volume is proportional to the pressure difference, $\Delta P_{e}=P-P_{c l}$, where $P$ is the magma pressure when the eruption starts and $P_{c l}$ is the threshold pressure value under which dykes close at the chamber wall, ending the eruptive event. Before edifice destabilization, the system is about to erupt, such that this difference is given by $\Delta P_{e}(i)=P_{r}(i)-P_{c l}(i)$, with $P_{r}$ the threshold pressure for dyke initiation at the chamber wall. After the major flank collapse, magma pressure within the chamber decreases by an amount $\Delta P$ to the value $P(f)$, and the pressure difference becomes $\Delta P_{e}(f)=$ $P(f)-P_{c l}(f)$. Three different cases can occur: case 1 , when $\Delta P_{e}(f)$ is greater than $\Delta P_{e}(i)$, where the volume of magma erupted is larger than it would have been with no edifice collapse; case 2 , when $\Delta P_{e}(f)$ is less than $\Delta P_{e}(i)$, such that the volume of magma erupted is smaller than it would have been with no edifice collapse and, case 3 , when $\Delta P_{e}(f)$ becomes negative, which means that the incipient eruption is aborted and there is no magma erupted. 
Figure 7: Evolution of the erupted volume of magma following the removal of the upper $20 \%$ of a conical edifice with a slope of 30 degrees. Results are presented as a function of the reservoir and edifice radius. Calculations are performed for a spherical reservoir filled with incompressible magma. Crustal Poisson's ratio is equal to 0.25 . Three different values for depth to the top of the magma reservoir are considered: a) $0.5 \mathrm{~km}$ depth, b) $1 \mathrm{~km}$ depth, c) $3 \mathrm{~km}$. The dashed lines approximately define the limits between the various cases defined in figure 6. Crosses are for calculations also performed in 3D with an asymmetric flank collapse.

Figure 8: Evolution of the erupted volume of magma following the removal of the upper $20 \%$ of a conical edifice with a slope of 30 degrees. Results are presented as a function of the reservoir vertical semi-axis and edifice radius. Calculations are performed for a prolate reservoir with a top at 1 $\mathrm{km}$ depth, filled with incompressible magma. Crustal Poisson's ratio is equal to 0.25 . After the edifice partial collapse, the volume of magma erupted is always smaller than it would have been in absence of edifice collapse (case 2 of figure 6).

Figure 9: Edifice geometries considered. A) The initial edifice shape before the sector collapse. B) The truncated final edifice shape when the upper $20 \%$ of the original edifice has been removed. C) The horseshoe-shaped crater of the final edifice when the $20 \%$ of the original edifice has been removed by a sector collapse. The edifice represented has a radius of $1 \mathrm{~km}$ and a slope of 30 degrees. The scale bar shows edifice height in meters. 

Clicdeprting

$\begin{array}{ll}1 & 1 \\ 1 & 3 \\ 1 & 6 \\ 3 & 1 \\ 3 & 3 \\ 3 & 6\end{array}$
Symmetric collapse \\ Erupted Vol without collapse}

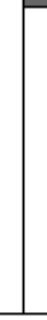

1
0.59
0
1
0.92
0.58

Asymmetric collapse

3

6 


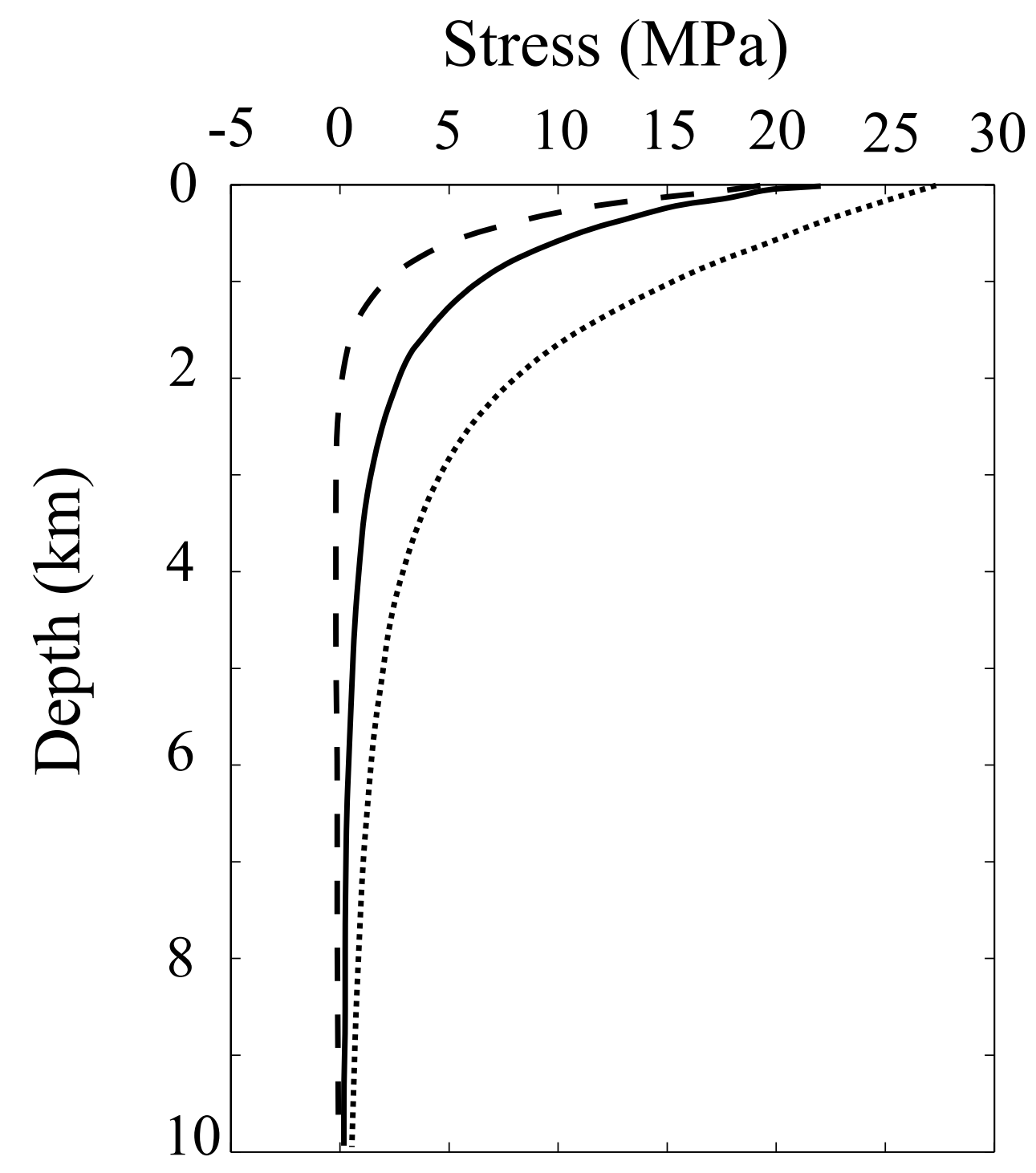


a)
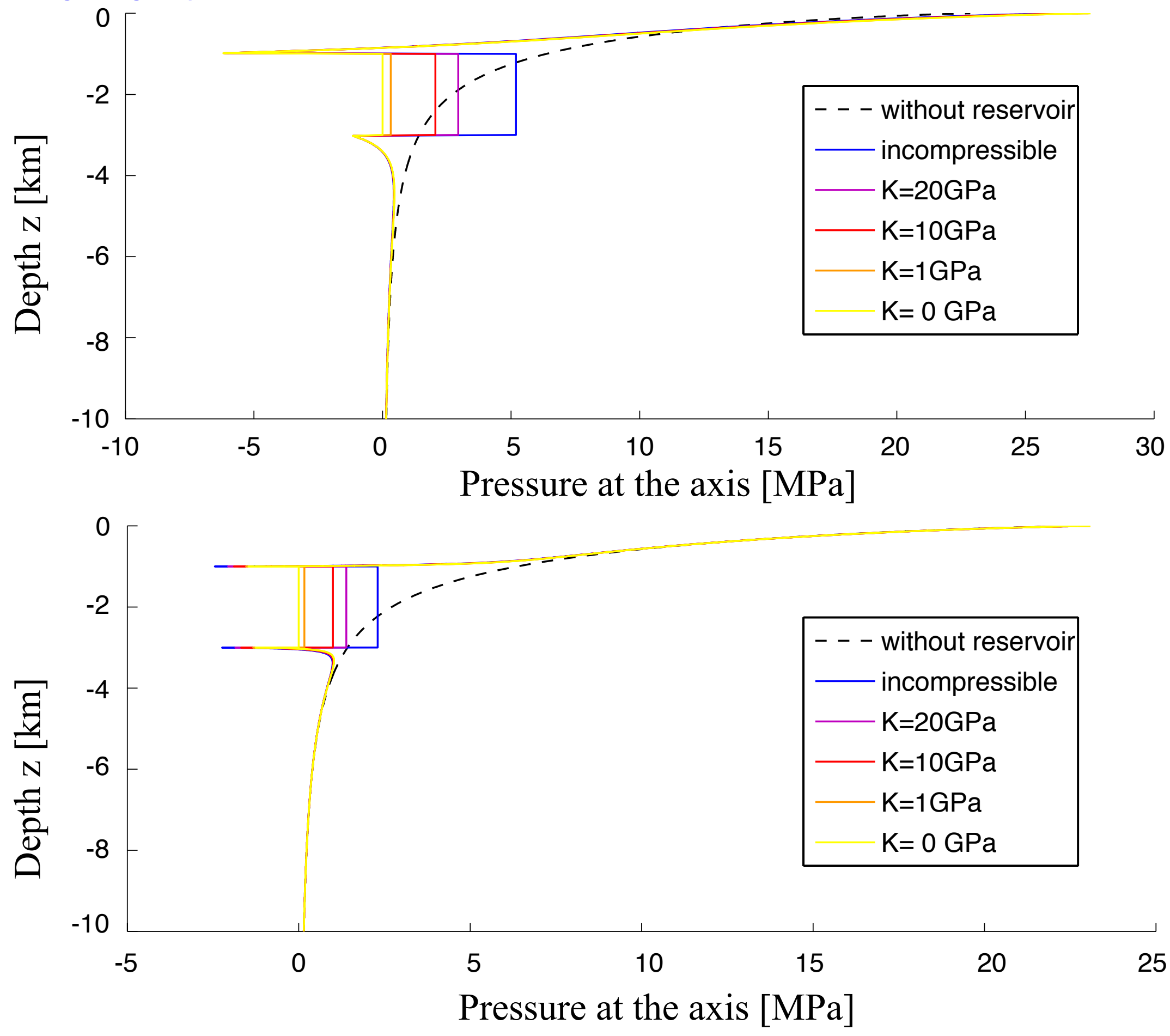

b)

Pressure at the axis [MPa] 


\section{Figure3}

Click here to download Figure: Figure3.pdf

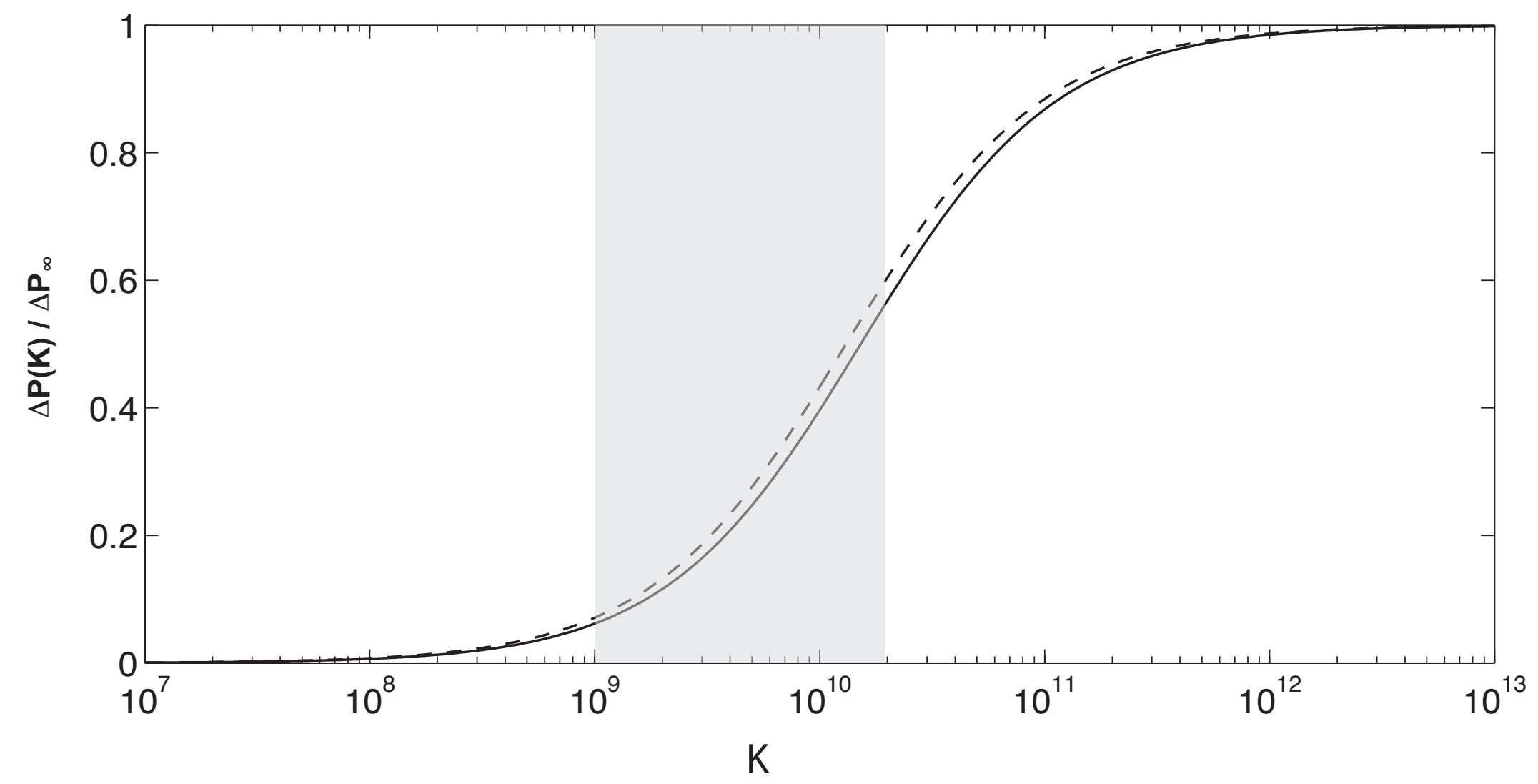


Click heread download Figure: Figure4.pdf
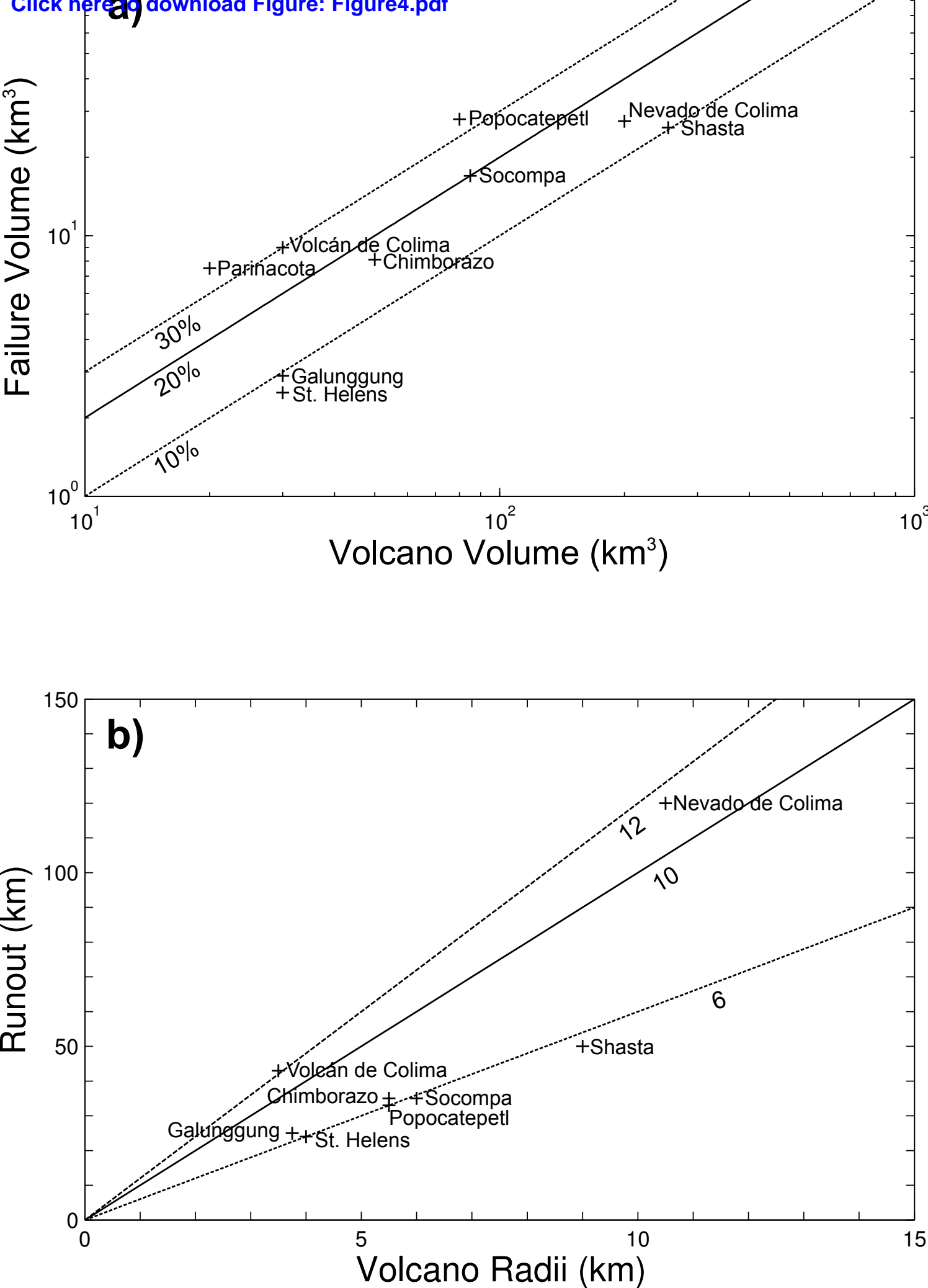


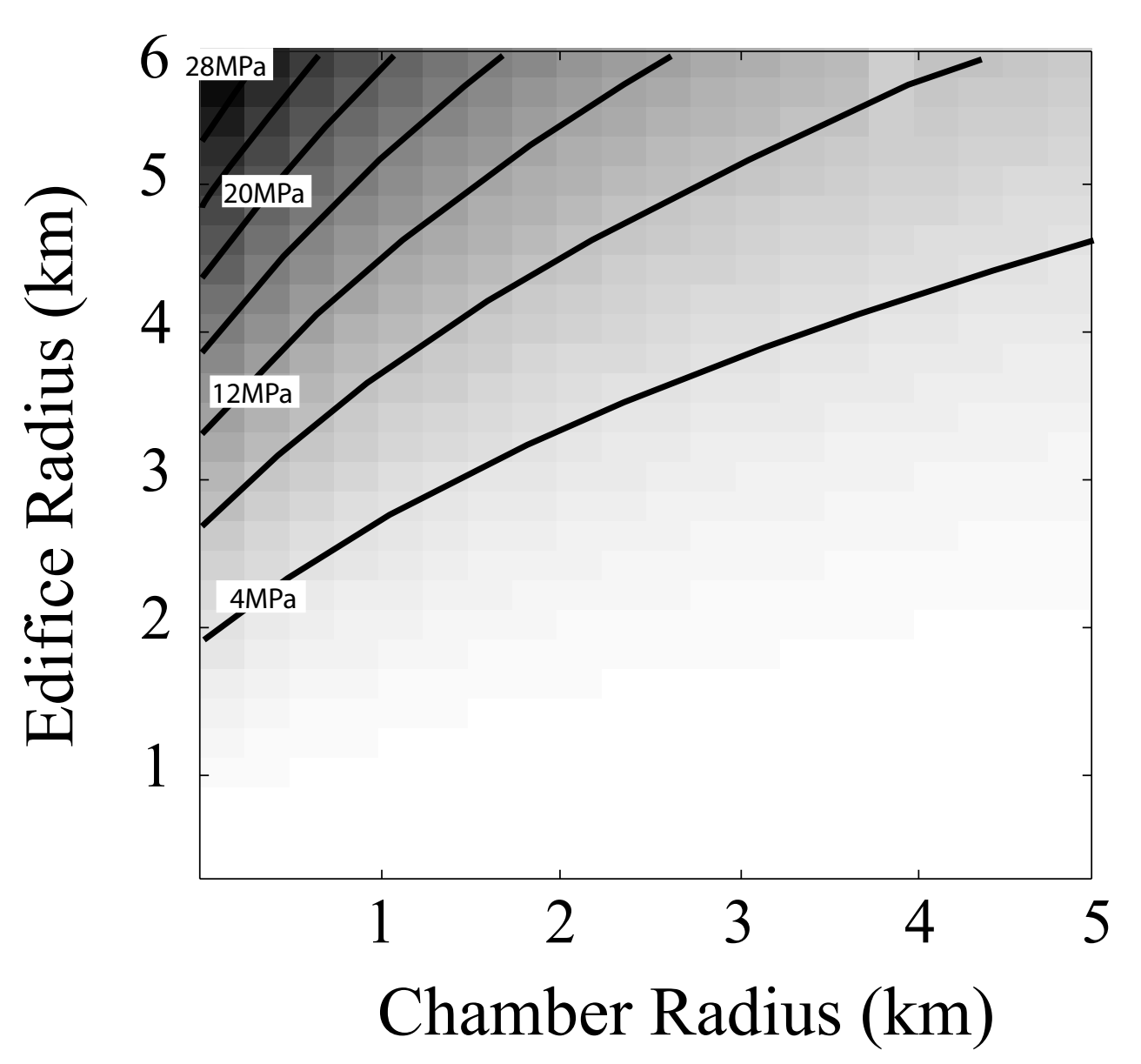

$\triangle \mathrm{P}(\mathrm{MPa})$

32
28
24
20
16
12
8
4

28

24

20

6

12

8

Chamber Radius (km) 


\section{Figure6}

Click here to download Figure: FIATE
Cligur.pdf

(a)

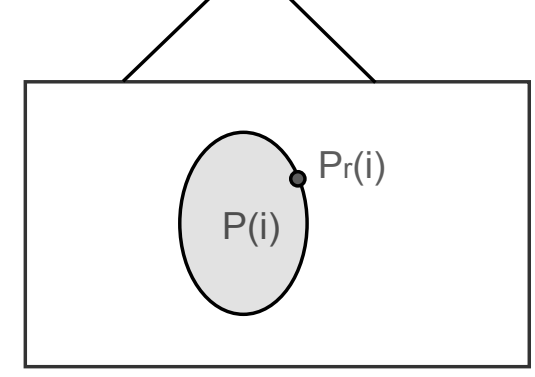

EDIFICE

PARTIAL

COLLAPSE

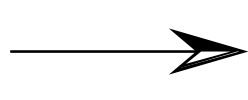

(b)
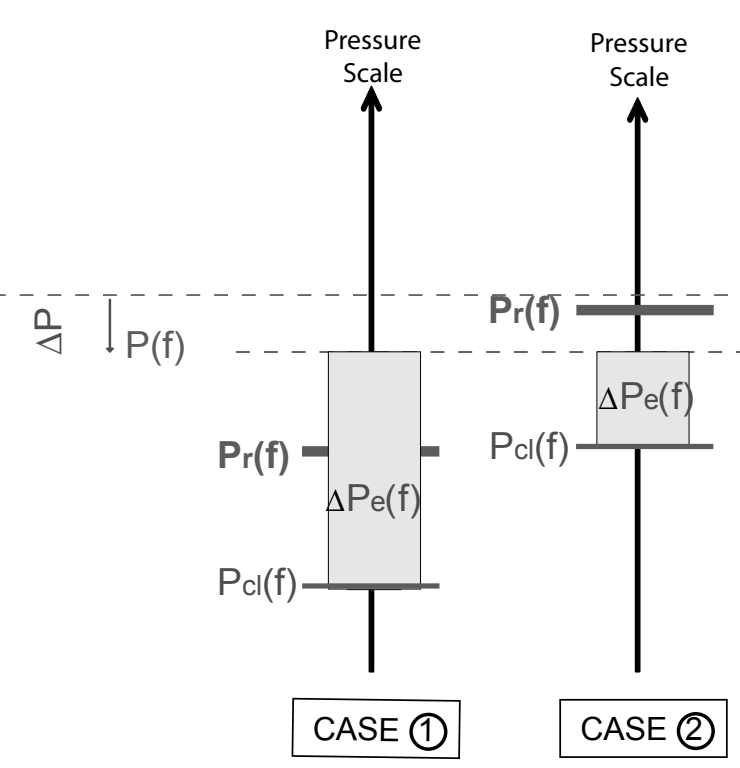

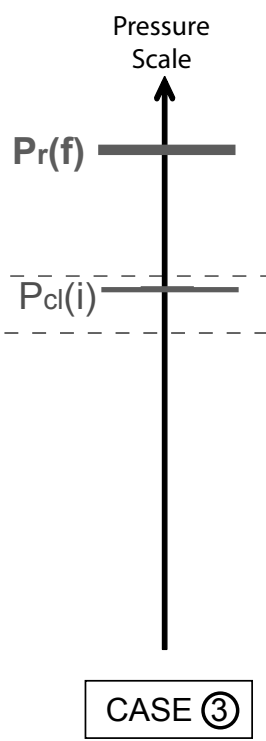

FINAL STATE

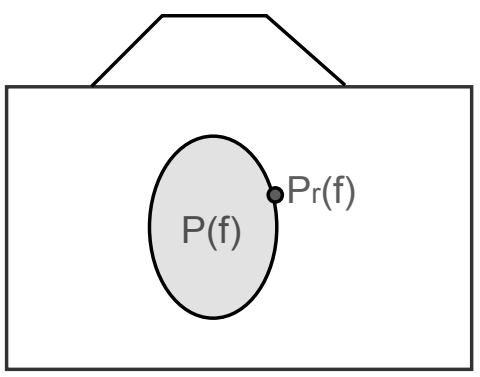

(3) 


\section{$\begin{array}{ccccccc}\text { Erupted Vol./Erupted Vol. } & 1 & 0.8 & 0.6 & 0.4 & 0.2 & 0 \\ \text { without collapse } & & & & & & \end{array}$}

Chamber top at $0.5 \mathrm{~km}$ depth Chamber top at $1 \mathrm{~km}$ depth

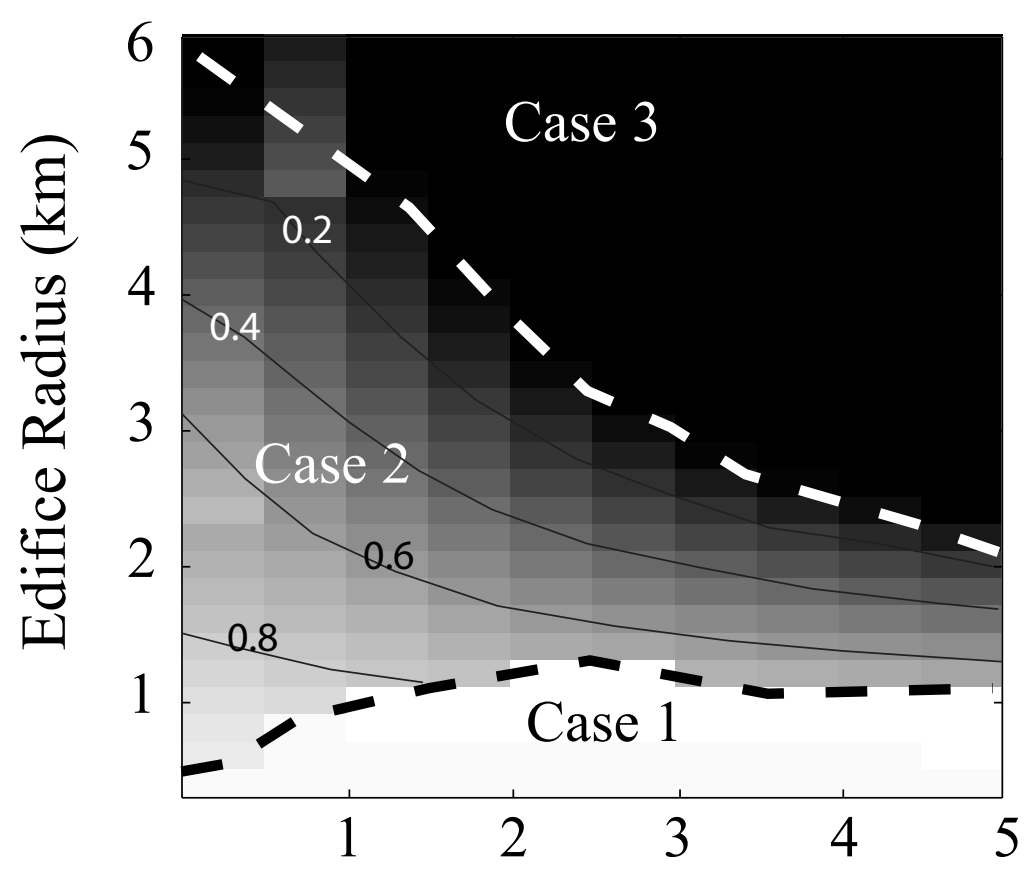

a) Chamber Radius (km)

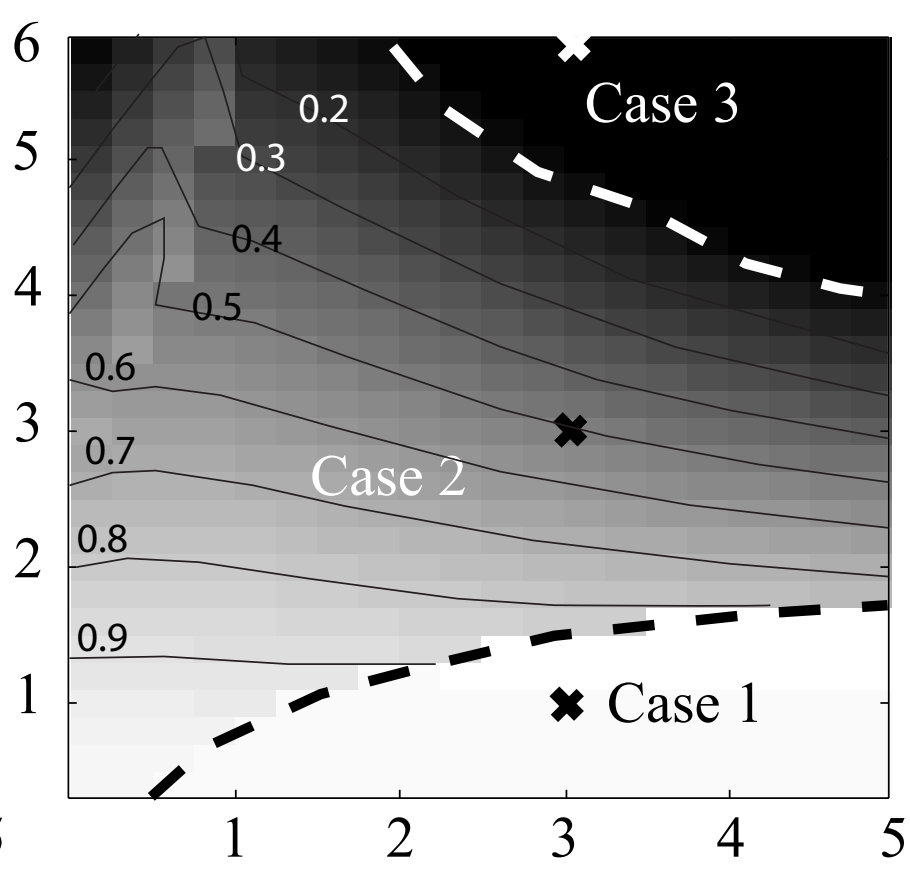

b) Chamber Radius $(\mathrm{km})$
Chamber top at $3 \mathrm{~km}$ depth

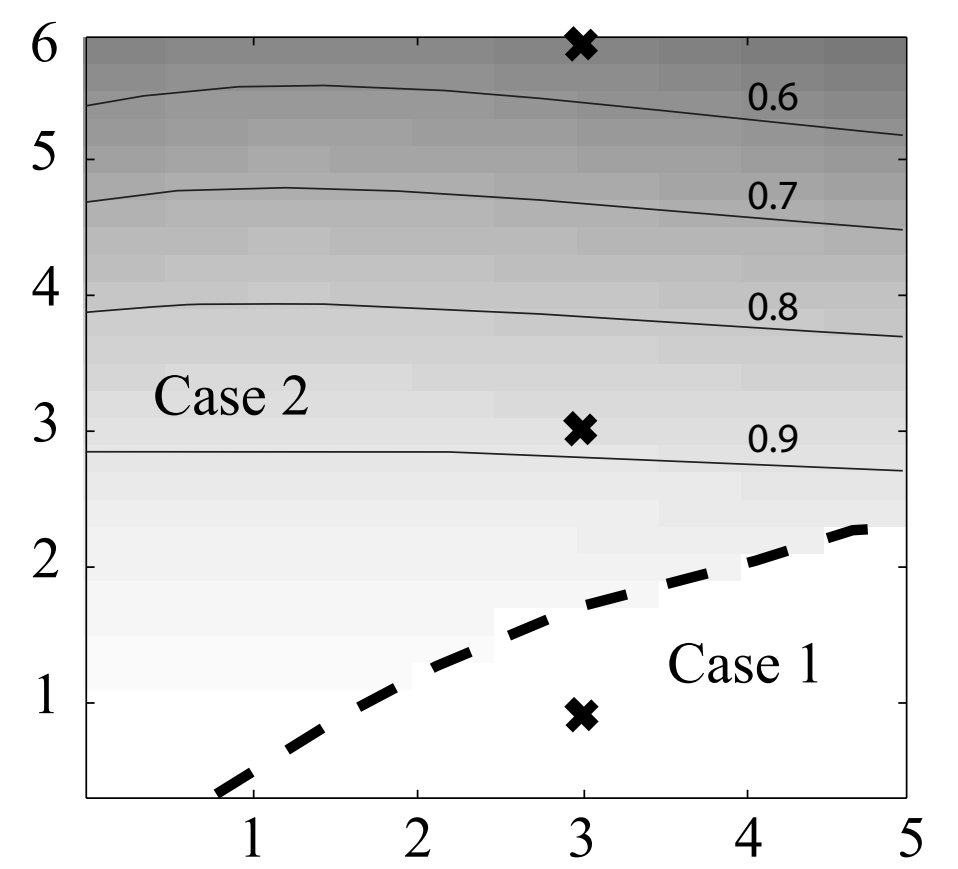

c) Chamber Radius (km) 
Erupted Vol./Erupted Vol.

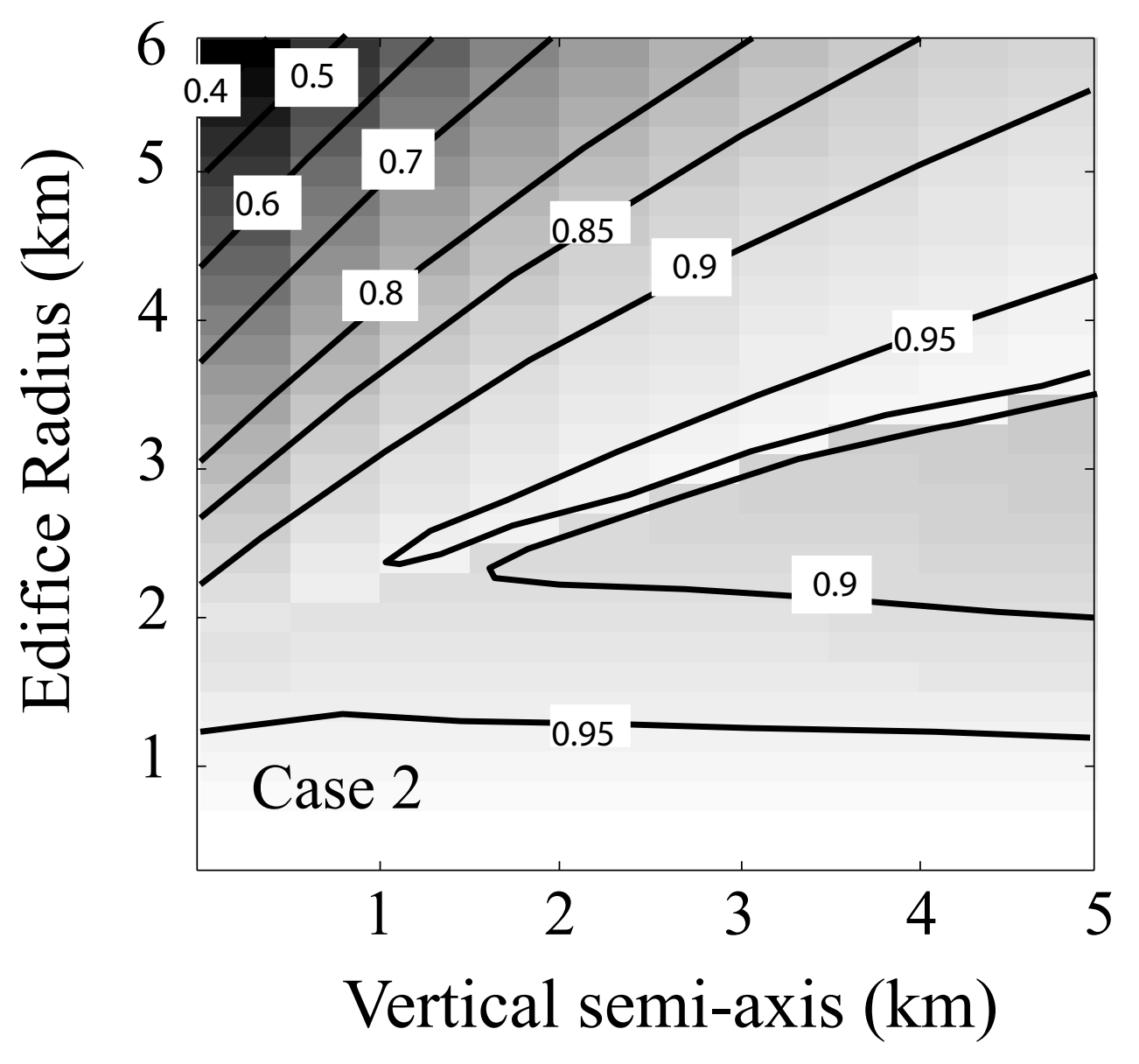

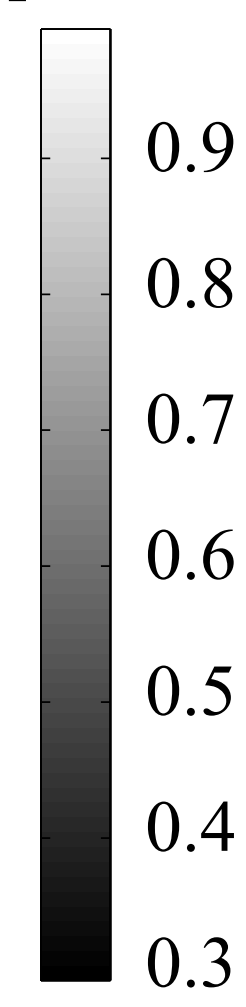

0.9

0.8

0.7

0.6

0.5

0.4

.3 without collapse 
Figure 9

Click here to download Figure: Figure9.pdf
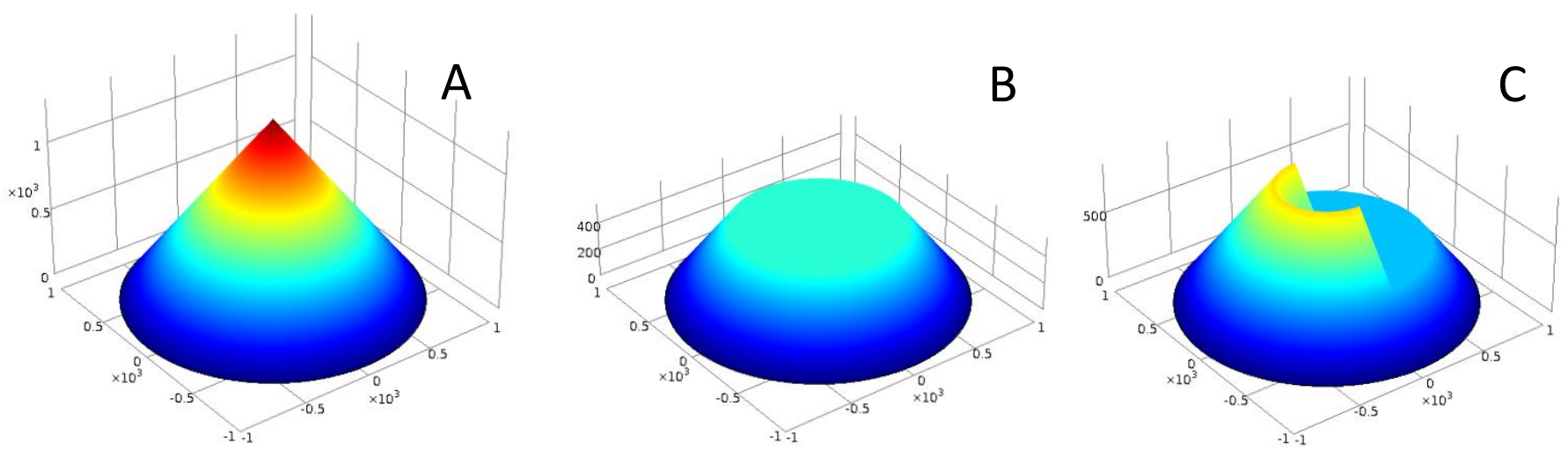

$\begin{array}{lllllll}0 & 100 & 200 & 300 & 400 & 500 & 600\end{array}$ 